International Journal of Agriculture, Environment and Bioresearch

Vol. 06, No. 04; 2021

ISSN: $2456-8643$

\title{
GOVERNANCE AND SUSTAINABLE FOREST MANAGEMENT IN GHANA AN ASSESSMENT OF THE VOLUNTARY PARTNERSHIP AGREEMENT
}

\author{
Gordon Kofi Sarfo-adu \\ Corporate Planning Manager ,Department Of Corporate Planning, Monitoring And Evaluation , Forestry \\ Commission, Ghana ,+233244286127 Or +233208420472 \\ Gladys Nkrumah, Phd \\ Lecturer ,Department Of Management And Human Resource, Ghana Communication Technology University \\ https://doi.org/10.35410/IJAEB.2021.5655
}

\begin{abstract}
This study to assess the role of governance systems in sustainable forest practices in Ghana using the experience of the Voluntary Partnership Agreement. It was underpinned by four main objectives: rationale for Ghana's ratification and obligations inherent in the Voluntary Partnership Agreement VPA; the institutional structures for implementing the VPA in Ghana; VPA enforcement and forest sector trade; and constraints in the VPA enforcement process. The policy arrangement approach and complexity of joint actions provided the theoretical framework for the study. The qualitative approach within the interpretivist research paradigm was employed for the study. Essentially, the VPA was ratified as a way of speeding up good governance process in the forestry sector of Ghana, promoting sustainable management of forest resources, enhancing and sustain the trade relationship with the EU. Meeting the requirements of the VPA has led to the institutionalization of relevant structures and mechanisms within and beyond the Forestry Commission including the use of technology-enhanced tracking and independent monitor for counter verifications which helps in detection of illegal wood harvesting. The VPA together with the established enforcement structures has had far reaching positive implications on the forest sector which are discussed in the study. The study, however, observed some challenges which affect the full realization of the expected benefits associated with the VPA. The study concludes that a policy even if originates from external source is more likely to be embraced if it does not challenge but feeds into government's prevalent activities, the legitimacy of that agreement/policy and enforcement remains higher. Secondly, the VPA is an external mechanism which has been localized and infused with ongoing projects to provide novel and innovative mechanisms for supporting Ghana's desires and quest to manage forests better, improve peoples' livelihoods, and protect natural resources. The study makes recommendations which includes the use of stakeholder consultations and workshops to help to address interagency coordination problem which will help optimize the enforcement of the VPA.
\end{abstract}

Keywords: Governance, Sustainable, Forest Management, Policy.

\section{INTRODUCTION}

Policy-makers world over has come to terms in their national forest plans and in the international forest policy arena the relevance of sustainable forest management to reduce forest loss and 
enjoy the benefits associated with sustainable ecology (Tritschet al., 2020; Jafari et al., 2018; McDonald \& Lane, 2004). Deforestation and forest degradation remain the second leading anthropogenic cause of carbon dioxide emissions which continues to increase global warming (Andrée et al., 2019; Houghton \&Nassikas, 2018; Intergovernmental Panel on Climate Change, IPCC, 2007). The Intergovernmental Panel on Climate Change (IPCC) estimates that deforestation and forest degradation account for approximately 17 percent of global greenhouse gas (GHG) emissions (IPCC, 2007). This suggests that increasing rate of deforestation and the destruction of forest resources harms global sustainability. Consequently, there have been efforts at the global level for international co-operation towards sustaining forest resources to store more carbon and to reduce the impact of carbon dioxide emissions. The role and value of forests have made their management generate internationally distinct policy responses.

The governance approach has implications on how people and groups interact with forests; in that regard, sustainable forest governance approaches have been advocated by different stakeholders. According to McDonald and Lane (2004), policy-makers in many countries recognise in their national forest plans as well as in the international forest policy arena the value of sustainable forest management (Tritsch et al., 2020). The connect between governance systems and sustainable forest management was championed by Dietz et al. (2003) to demonstrate an approach in which the policy process gets dominated by networks of different actors powered by co-operation and consensus orientation (Maraseni et al., 2019). A governance system that underscores the relevance of networks rather than the government acting alone helps in sustainable forest management (Fasona et al., 2019). Sustainable forest management (SFM) connotes a management regime that balances the social, economic and ecological values associated with forest and considers these values for future generations (Riccioli et al., 2019). The authors aver that adopting SFM practices has implications on the social, economic and ecological pillars of sustainable development.

Many national governments have institutions, policies and structures to regulate sustainable forest practices. Optimizing the operationalization of these national structures and institutions primarily in developing countries requires an array of a network of actors rather than the government acting alone (Yamaki, 2017; dos Muchangos et al., 2017). Thus, promoting SFM requires several institutional factors (Faggin\&Behagel, 2018); including precursors of consensusbuilding on 'sustainability practices' (Kahsay\&Bulte, 2019); and the processes which make SFM institutionalized by rules and effective deployment (Meyer \&Baltes, 2004).

From the preceding, it could be inferred that institutions and governance structures are very crucial to sustainable forest management practices in a country (see also Roche, 2017; Feka, 2015; Gossum et al., 2011); however, ensuring the effectiveness of these elements require some precursors and a 'push factor'. The Rio Declaration calls on all nations of the world and other civil society actors to reduce the growing trend of deforestation and all other human threats to the sustainability of forest biodiversity. Participation of stakeholders in forest management has increased in recent times and will become increasingly important (Baig et al., 2019). The critical role of international law, multilateral and bilateral relations in the sustainable management of the world forest heritage, negotiations for the adoption of the International Convention in the 
Vol. 06, No. 04; 2021

ISSN: $2456-8643$

framework of the United Nations Forum on Forests (UNFF) has been advocated and pragmatic efforts have been undertaken in that regard (Dlamini \&Montouroy, 2018; Kuokkanen 2006).

Accordingly, the international governance and regulatory context for sustainable forest management appear to be underpinned by multilateralism and cooperation, hard and soft law, norms and discourses and private self-regulation. The European Union Forest Law Enforcement on Governance and Trade (EU-FLEGT) Action Plan seeks to promote widespread sustainable forest management and relies mainly on transnational actors and international law in its operationalization. The EU FLEGT sets out EU custom regulation through Voluntary Partnership Agreements (VPAs) which is a bilateral agreement between the EU and wood exporting countries with instruments aimed at promoting sustainable practices within the forest resources value chain.

The whole idea is that EU member countries have become more concerned with the legal origin of the timbers that come to their market and want to curb illegal logging world over. Ghana has in the region of " 2.6 million hectares of forest reserves dedicated to the production, about 500,000 hectares of unreserved forests, as well as an additional 2 million hectares of cropland that also produce timber. Independent studies estimate the annual timber production of Ghana to be about 3.5 million $\mathrm{m}^{3}$ of round wood", half of which is destined for export markets ${ }^{1}$. Revenue from timber exports approximately makes the forest sector the $4^{\text {th }}$ largest contributor to GDP in Ghana. The EU is a valuable market for Ghana which accounts for forty-three per cent of the value of total exports and thirty-three per cent of total volume ${ }^{2}$. Ghana's share of the EU's tropical timber imports is about 3\%. Consequently, the EU is valuable wood trade partner to Ghana, the latter has subsequently become a signatory to the VPA and is therefore required to adequately put in place robust governance systems and structures to meet the criteria as set out, which should have implications on sustainable forest management. The study examines how the VPA through its arrangements influences sustainable forest management in Ghana along the forest value chain. To contextualize the study and for a detailed assessment, the study adopts the experiences of the Goaso and Asankrangwa Forest Districts in the Brong-Ahafo and Western Regions of Ghana, respectively.

The driving research questions are clear cut. Why did Ghana ratify the VPA and its obligations in the agreement? How has Ghana retooled its institutional structures for implementing the VPA?How has implementation of the VPA influenced forest resources exploitation and trade? What are the key constraints encountered in the VPA implementation process? Beyond this introduction, the rest of the paper is organized as follows. Section two is dedicated to a rigorous review of the literature on governance and sustainable forest management, while section three discusses the methodological approach underpinning the study. The results of the research and discussion are presented in section four with conclusions that can be distilled from the paper presented in section five.

\section{LITERATURE}


Vol. 06, No. 04; 2021

ISSN: $2456-8643$

\subsection{The Concept of Natural Resources Governance}

Generally, there are three fundamental natural resources which are soil, water and vegetation. The latter is conceptualized to entail biodiversity, flora, fauna and forests which manifest in many forms to create the foundation for human survival and progress. Forest resources are very crucial for ecological and socio-economic services. Due to the socio-economic benefits inherent in forests products coupled with increasing population growth and poverty, people and groups do exploit them; consequently, this causes incessant pressure on forests which continues to cause degradation. It is within that context that various governance approaches have been advanced to help ensure sustainable forest management.

The idea of governance has been applicable in the literature to connote a complex set of structures and processes, both public and private as well as the interaction among these different entities which produce both compromises, conflicts and decisions. Various bodies and entities have defined the concept, although the central point of interaction among multiple units and actors remains fundamental. In this section, the chapter highlights some definitions of governance and its implications for sustainable forest management.

The Commission on Global Governance (2015) defines 'governance' to mean 'the sum of the many ways individuals and institutions, both public and private, manage their everyday affairs. In other words, it suggests an enduring process by which conflicting or diverse interests may fashion out to reach compromises and co-operative actions reached.

On their part, the World Bank (2001), "defines governance to mean how power is exercised in the management of a country's economic and social resources and for that matter environmental resources". The World Bank identifies "three distinct connotations of governance: (i) a form of the political regime; (ii) the process by which authority is exercised in the management of a country's economic and social resources (including environmental resources) for development; and (iii) the capacity of governments to design, formulate, and implement policies and discharge functions". This definition and categorization provide a more comprehensive overview of the concept; it demonstrates the relevance of state power or public entity in the governance process, a manner in which such state power or public office is used to manage resources and finally the processes, structures and systems for promoting effective management or exercise of power which also entails avenues for other non-state actors to participate in the process.

UNDP (2013) conceptualizes Governance to mean the exercise of economic, political and administrative authority to manage a country's affairs at all levels. It has implication for management of forest resources as states do have agencies and specific arrangements for exercising authority in management of natural resources including forests. These governance arrangements encapsulate mechanisms, processes and institutions through which citizens and groups articulate their interests, exercise their tenure rights, meet their obligations and mediate their differences. 
Global Governance Commission (2013) defines governance as the sum of the many ways individuals and institutions, public and private, manage their common affairs. It is a continuous process through which compromises are taken by reconciling diverse interests come to a more coherent term to adopt co-operative action. Doing so requires formal institutions and agencies who have been given authority as such to enforce compliance together with informal arrangements that people and institutions commonly come to terms with in the course of their interactions.

The governance aspect of the above conceptualization is reiterated by Demers (2009) who explains governance to mean the interactions among structures, processes and traditions to determine how power is exercised to result in how decisions are made, and how other stakeholders get involved in the decision taking space. From Demers' account, governance basically involves power, relationships and accountability.

Applying the above definitions to the forestry sector, it connotes the various agencies with power and authority to make and enforce forestry regulations, policies as well as their interaction with other non-state actors within the forestry value chain. In other words, governance systems entails the processes, institutions, agencies and actors involved in the making and implementation of relevant environmental and forest related regulations and decisions to safeguard order in the sector. Against that backdrop, Fokier et al (2005) define natural resource governance to connote the processes of decision-making involved in the control and management of the environment and natural resources. They quizzed "are they (forest related policies) made behind closed doors or with input from the broader public?"

That regard, it is expected that forest related state agencies and officials adopt the best possible methods, processes, mechanisms to ensure forest resources are managed appropriately whilst relevant stakeholders are provided with right mechanisms to participate and benefit from forest resources without compromising forest sustainability. This leads to the idea of good governance which among other things, calls for a more participatory, transparent and accountable approach to forest governance. The notion of good governance facilitates an effective and equitable access to forest resources and also promotes the rule of law. More importantly, it ensures that environmental and forest related priorities are pillared on broad consensus in society and that the voices of the poorest and the most vulnerable are heard in decision- making over the allocation of development resources. This is summed up by Fokier et al (2005) "it is also about the manner in which decisions are made...principles such as inclusivity, representivity, accountability, efficiency and effectiveness, as well as social equity and justice, form the foundation of good governance".

The idea of governance gradually emerged only after appreciation of the fact that various or combination of means, processes and actors is crucial for dealing with natural resource problems than just by depending on government and its agencies (Sampford, 2012). Although there is no universally acceptable definition of governance, essentially, it connotes an interaction and interplay of groups and varying stakeholders in the management of particular natural resources. In Samford's explanation, he maintains that governance involves a combination of ethical 
standard setting, formal rule making and institutional design by which organizations attempt to ensure that they live up to the values by which they justify themselves to the community in which they belong (Tuxill, \&Nabhan, 2011). As has been indicated, natural resource governance involves varying actors and organizations whose role are crucial; the actors include: state actors, non-governmental actors, private sector, media, activists, research and scientific actors (Sampford, 2012). It suggests that governance entails governmental actors (state agencies and institutions) as well as non-state actors. In that context, Balsiger and Debarbieux (2011) posit that the concept of governance points at more or less formal arrangements adopted for dealing with public issues and involving a wide range of participants, government being only a member of the actors. The era where natural resource management used to be the sole responsibility of government and state actors seems to be paving way for other actors to complement efforts of government.

Accordingly, the conceptualization of governance in this thesis adopts an inclusive typology which dwells on interplay between government as well as non-governmental actors and not a minimalist view which restricts it to government (Plumptre\& Graham, 2000; Rhodes, 1996). Consequently, forest governance suggests a continuum of decision-making arrangements involving multiple actors and institutions at varying levels to ensure compliance with best practices and standards to ensure sustainable forest practices. There are different forms of forest governance which underscore the essence of multiple actors. There are different approaches for managing forest resources which include cooperation, partnerships, collaboration and comanagement which all hinge on some form of shared responsibility between the state and nonstate actors (Plummer \& Fitzgibbon, 2004).

In a more recent study, Gerlak et al. (2019) aver the need to adopt an interdisciplinary approach by incorporating learning theories from other fields to encourage the idea of learning in environmental governance processes. The authors argue on "the need to find opportunities to bridge conceptual and theoretical divides across the environmental and natural resource learning research community, while still accommodating the rich insights from diverse disciplines that speak to learning" (p. 1080). This is an exciting call which does not only argue for single-loop learning but a double loop which involves more significant interaction, participation and feedback such that the entire system continues to learn and takes inspiration from reactions from user and target groups.

\subsection{Sustainable Forest Management}

The idea of sustainable forest management had been practiced as far back as "the eighteenth century when early foresters in Europe advanced an understanding of natural forestry productivity as well as its regeneration through silviculture to sustain a continuous supply of wood, game, and other products for human use and consumption" (Wiersum, 1995). The primary rationale of this practice was "the quest to counter the social and economic disturbance associated with shortages of timber, whether for local use or as the basis for a community export economy" (Wiersum, 1995). 
Vol. 06, No. 04; 2021

ISSN: $2456-8643$

The concept and practice of sustainability in forestry have evolved to greater depth and implications. The vastly expanded understanding of the complex functioning of forest ecosystems, and an acknowledgement of the full range and diversity of resources, values and ecological services that forests represent, has created new challenges and opportunities (Sample, 2004).

\subsubsection{Contemporary Notion of Sustainable Forest Management (SFM)}

The concept of "SFM was first set out at the United Nations Conference on Environment and Development (UNCED), often referred to as the Earth Summit, in Rio de Janeiro, in 1992". The discussions and negotiations chiefly centered on the management, conservation and sustainable development of forests and the possibility to institute international instruments for forests management that would be legally binding on all countries and agencies. Notwithstanding the efforts made, agreement on a legally binding forest convention did not materialize. Still, it led to the agreement and enforcement of "Non-Legally Binding Authoritative Statement of Principles for a Global Consensus on the Management, Conservation and Sustainable Development of All Types of Forests" which have commonly become known as the "Forest Principles" and Chapter 11 of Agenda 21 on "Combating Deforestation".

The contemporary notion of "sustainable forest management (SFM) encompasses socio-cultural, economic, and ecological (environmental) components of management adopted by the UN Conference on Environment and Development in Rio de Janeiro in 1992" (Kaila \&SalpakiviSalomaa, 2004). One of the results of the Summit was the declaration of the Forest Principles for Sustainable Forest Management and the first global agreement on forest management sustainability.

SFM encompasses an approach which seeks to keep forest ecosystems healthy with a simultaneous emphasis on ecological, social, and economic considerations with the three aspects being mutually dependent. Sample (2004) explains that it is impossible to get forest ecosystems protected without the economic and social needs of the local people being incorporated in the conservation processes. Against that backdrop, the International Tropical Timber Organization (ITTO, 1992), defines SFM as: "the process of managing the forest to achieve one or more specified objectives of management concerning the production of a continuous flow of desired forest products and services without undue reduction of its inherent values and future productivity and undue undesirable effects on the physical and social environment".

The final phrase in the definition "without undue undesirable effects on the physical and social environment" tends to demonstrate the interrelations between social, economic and ecological elements. This has explicitly been mentioned in the definition by Ministerial Conference on Protection of Forests in Europe (MCPFE, 1993) which conceptualized SFM to denote "the stewardship and use of forests and forest land in such a way and rate, that maintains biodiversity, productivity, regeneration capacity, vitality and their potential to fulfil, now and in the future, relevant ecological, economic and social functions, and that does not impact negatively on other ecosystems." 
Vol. 06, No. 04; 2021

ISSN: $2456-8643$

On their part, Thompson et al. (2009) explain "SFM to the flow of goods and services and also its ability to maintain forest ecological processes essential for maintaining ecosystem resilience. In other words, SFM entails the capacity of a forest ecosystem to recover the following disturbance or to relate to the various uses and functions of the forests (such as for wood production, collecting non-wood forest products, recreation, protection of soil and water resources, biodiversity conservation, carbon sequestration); and aims to maintain and enhance social, cultural, environmental and economic values of forests for the benefit of present and future societies".

At its General Assembly meeting in 2007, the United Nations (UN) conceptualized sustainable forest management to mean "a dynamic and evolving concept [which seeks] to maintain and enhance the economic, social and environmental values of all types of forests, for the benefit of present and future generations". The definition has in all intent and purposes to maintain current forests from further destructions and to seek measures to improve their conditions whilst not also forgetting the social and economic values.

Arguing from similar context, the International Tropical Timber Organization conceptualizes "SFM to mean the process of managing forest to achieve one or more specified objectives of management concerning the production of a continuous flow of desired forest products and services without undue reduction of its inherent values and future productivity and undue undesirable effects on the physical and social environment" (ITTO, 2005). Whilst this definition also puts emphasis on sustaining the longevity of forests and their inherent ability to provide similar essential services to future generations, this is subtle and implied in their conceptualization when they put it ' '... a continuous flow of desired forest products and services without undue reduction of its inherent values and future productivity". The definition is also concerned with how to balance the idea of environmental sanctity with that of socio-economic conditions of communities which they term "...without undue undesirable effects on the ...social environment". By and large, the foregoing definitions reiterate the need to ensure a harmony between ecological protection in order to continually derive the benefits thereof and not also being oblivious of the socio-economic conditions of people. It is against this backdrop that many scholars tend to associate the notion of sustainable forest management with the notion of sustainable development as both of these put emphasis on the three cardinal values of environmental sphere, economic sphere and the social sphere with the use of criteria and indicators (see Linsar et al, 2019; Schlaepfer, 2007).

Whilst Schlaepfer (2007) reiterates the need for appropriate criteria and indicators for examining how the governance regime affects the environmental, social and economic spheres, the ITTO (2005) also mentions the need for '....more clearly specified objectives of management...'. Both are of the notion that there should be some pre-stated objectives or indicators/criteria that should help judge the extent to which SFM has fared and whether indeed all relevant spheres are given needed attention. Arguing from this thinking, the literature highlights that sustainable management of forests requires two key phases; firstly, the need to develop forest management plans which will have some clear-cut objectives as well as criteria and indicators to achieving these plans. The second phase involves enforcement and monitoring of the management plans 
Vol. 06, No. 04; 2021

ISSN: $2456-8643$

(Ahimin et al, 2019) to ensure all relevant benefits are derived. As has been highlighted above, SFM hinges on some clear-cut benchmarks to ascertain whether indeed a governance approach has contributed to SFM. It is in this regard that such standard frameworks have seen the development criteria and indicators for monitoring and assessing this concept (Spies et al, 2019).

Growing attention to the social and economic spheres of "SFM became increasingly influential with the increasing rates of deforestation and degradation of the world's forests and has become an integral component of international agreements and forest policy deliberations" in the past two decades.

\subsection{Theoretical Framework: Policy Arrangement Approach}

In this research, the policy arrangement approach (PAA) was used to frame the study. The concept of policy arrangement suggests temporary stabilization of the content and organization of a particular policy domain (Van Tatenhove et al, 2000) involving structures formed through processes and interactions among policy actors and rules (Arts \& Leroy, 2006). This approach is more appropriate when a research hinges on the dimensions of actors, power, rules and discourse (Arts \& Van Tatenhove, 2004; Arts \& Leroy, 2006). The framework pays peculiar attention to (1) institutional contexts in which policy actors must operate, (2) the substance of policy-making and (3) the power relations between the policy actors involved (Wiering\& Arts, 2006). As this proposed study discusses impact of VPA implementation on governance and institutional structures of Ghana as well as impact on forest practices, the PAA framework is more appropriate to frame the study. this framework has been applied to analyze dynamics of forest policies elsewhere, including the Netherlands (Veenman et al, 2002), Belgium (Van Gossum et al, 2011) and South Korea (Park \&Youn, 2013).

The PAA as theoretical framework rests on two key philosophies; (i) political modernization and (ii) policy arrangements. Political modernization entails the ever-changing interactions between the state, the market and civil society in political domains of society within national borders and beyond which is manifested in through globalization and Europeanization (Arts \& Van Tatenhove, 2006). An implication is that forest decision processes do not rest with governments of one state or the traditional forest sector alone but polycentric in nature (Verbij, 2008).

The policy arrangement is discussed along following four dimensions: (a) actors and their coalitions involved in the policy domain; (2) the division of resources between these actors (b) the rules of the game and (d) discourses (Arts \&Goverde, 2006; Arts et al., 2006). This illustrated in the framework below. 


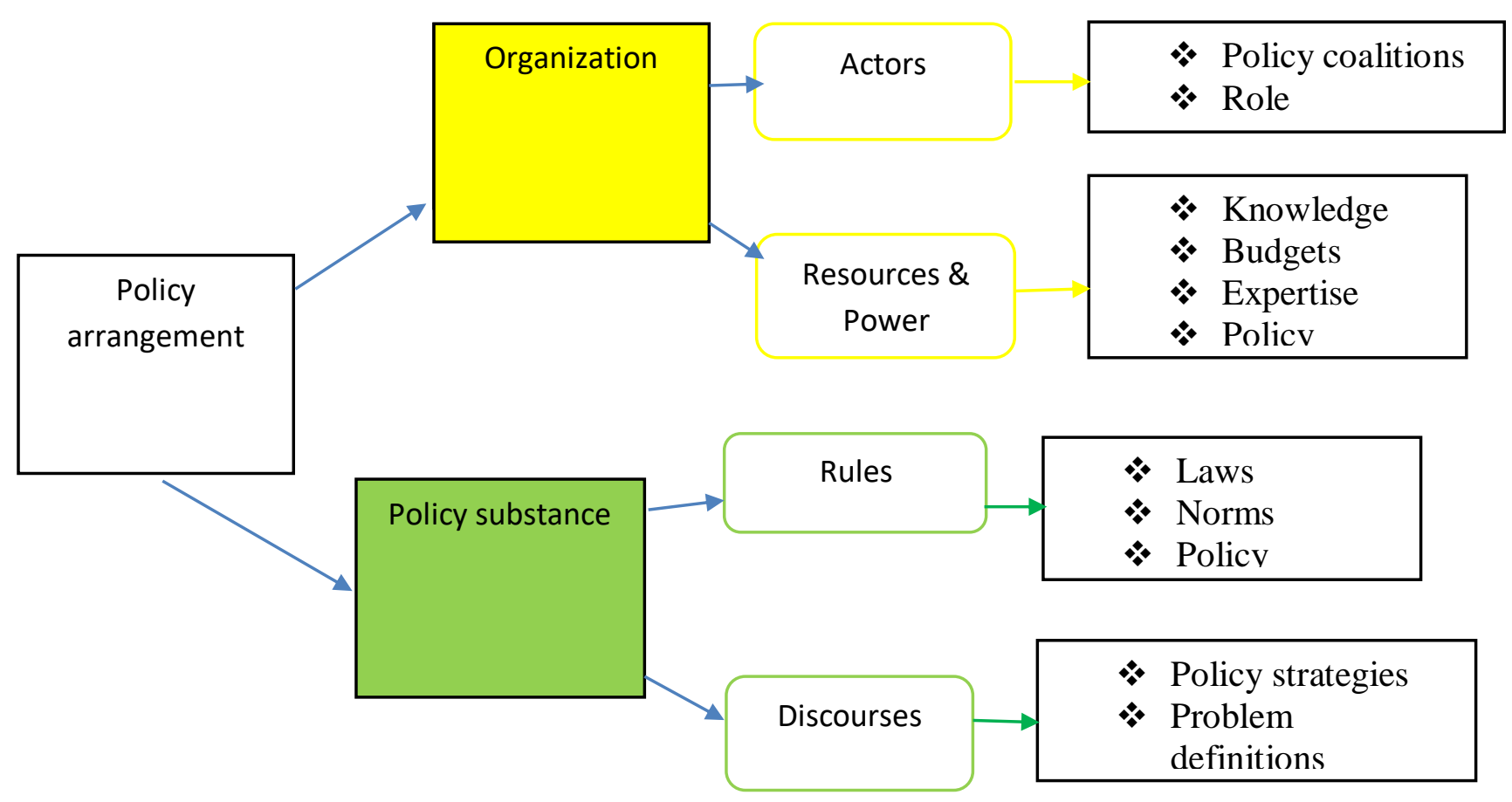

\section{METHODOLOGICAL APPROACH}

The study was carried out and organized within the interpretivist research paradigm. The interpretivist research paradigm has been explained by White (1999) to be "concerned with the meanings that people attach to norms, rules, and values that regulate their interactions. The author cautions that researchers should ensure not to impose their previous or prevailing understanding of norms, rules, and values of others but rather understand the beliefs and actions from the people's own point of view. The focus is not only on what respondents directly tell about the reasons for their beliefs and actions, but also on the social practices that underlie those beliefs. In other words, social practice gives meaning to social action (White, 1999, p. 49). The ontology of interpretivists considers reality as subjective and socially constructed with the researcher and the object (respondent) both involved in the knowing process. In other words, the researcher seeks to know the reality through the eyes of the respondent (Olson 1990). Thus, for the interpretivist researcher, reality is not a rigid phenomenon that is crafted at source by the researcher; rather it is a creation of those individuals involved in the research.

The study employs the qualitative approach of social research because the EU FLEGT and VPA implementation is a relatively new phenomenon which requires adequate exploratory study. This paradigm allows a researcher to have an in-depth understanding of the phenomenon under discussion especially if it is new which requires deeper insight (Creswell \& Clark, 2017; Yin, 2003; Creswell, 2013). Qualitative research involves the use of soft data in the form of gestures, 
Vol. 06, No. 04; 2021

ISSN: $2456-8643$

impressions, symbols of the respondents (Newman, 2007). With such unique attributes of qualitative approach, the researcher was able to make a very strong interpretation from interaction with the key informants.

The case study design is adopted for the study; a case is examined to understand an issue or provide input to an existing theory and a research work deploying the case study method may have single or multiple cases (Yin, 2017). The case study is to enable the researcher comprehensively and systematically gather enough data needed to respond to or achieve the research objectives. A case study is considered appropriate to describe the characteristics and contexts of a particular entity or organization.

In order to contextualize the implication of the FLEGT VPA implementation of sustainable forest management, the study was situated within two forest districts of Ghana (Goaso and Asankrangwa) which are districts which were the initial districts for the VPA implementation in Ghana.

The researcher used two main sources and types of data. Both primary and secondary sources of data were used to undertake the study. Primary data was elicited from respondents who are mainly key administrative officials of the relevant units/departments at the Forestry Commission whose positions make them relevant to the FLEGT VPA implementation. To contextualize the study, operational officers and managers at the Goaso and Asankrangwa Forest Districts were selected.

Secondary data came from journal sources, scholarly books, internet sources, published and unpublished materials relevant to the study. Again, documents from Ministry of Lands and Natural Resources, Forestry Commission of Ghana; Ghana-EU team bulletins and other releases were resorted to. The use of both primary and secondary sources of data is to enable verification of data and cross examination to enhance the reliability of data and research findings.

The purposive sampling technique was used to select relevant informants to participate in the study. With qualitative study, researchers do not place much emphasis on numbers but the relevance and quality of information that would be elicited from participants (Creswell \& Creswell, 2017). The purposive sampling technique is largely used to select unique cases that are very informative and a difficult-to-reach population (Newman, 2007). In this study, the purposive sampling technique was deployed to select key actors from the Forestry Commission which is the lead government institution for VPA implementation in Ghana and expected to contribute about eighty per cent of VPA implementation.

The study used in-depth interviews and semi-structured questionnaires as the main research instruments. In-depth interview "involves face-to-face interaction with key respondents. This research instrument is deemed appropriate because it enabled the researcher to have a detailed discussion with key informants who have the required information sought by the researcher. Indepth interview enables researchers to interact with key informants with the aid of interview guide, again researchers have the chance of asking further probing and follow-up questions to seek further clarifications on the information sought. In carrying out the study, an interview guide was developed and used to gather data from respondents. This data collection technique helped the researcher to get insights into the VPA implementation and brought forth other 
emergent ideas and knowledge. The interview technique was complemented with semistructured questionnaire which was used to validate the data obtained from the in-depth interviews".

All interviews were recorded and analyzed using the qualitative thematic analysis method. This analysis process involved five (5) key inter-related processes. The interview transcripts were organized by printing them out, putting the field notes into perspective. A table comprising five main columns was created with, a first column was designated as 'respondent' whilst the second column had the transcribed responses of the respondent verbatim. The third column was used to identify the key similarities in the narratives provided by various respondents' whist the fourth process involved identification of the differences between their submissions. A final column was used to deduce and identify emerging themes or trends from the responses. This led to the development of initial codes which were further revised and combined with other themes that have been presented in a more cohesive manner in the empirical study. In order to enhance reliability and validity, data from official implementation agencies were triangulated with views obtained from non-institutional actors sampled for the study. This made it possible to identify themes that clearly reflected the situation on the ground and this was even consolidated by relating them with more recent empirical literature relevant to the topic under study.

\section{RESULTS AND DISCUSSIONS}

The study was carried out and within the interpretivist research paradigm, specifically the qualitative approach was adopted. The study was contextualized within two forest districts of Ghana, the Asankrangwa and Goaso forest districts. Both primary and secondary sources of data were employed for the study. The purposive sampling technique was used to select relevant informants to participate in the study. Respondents were selected from the Timber Verification Department, Resource Management Support Centre (RMSC), the Forest Service Division (FSD) and the Timber Industry Development Division (TIDD) of the Forestry Commission. The study also involved a non-governmental organization, a private timber firm and selected community members. Data was gathered through in-depth interviews with respondents which were also triangulated with data from semi-structured questionnaires. Qualitative data were analyzed by coding, sorting out and subsequent thematic analysis.

\subsection{Relevance of the VPA and Rationale for Ghana's Ratification}

\section{Speeding up good governance process}

The study observed that the key reasons for Ghana's ratification of the VPA was to ensure a speeding up of good governance process in the forestry sector. Most of the interventions such as promoting transparency and accountability in the forestry sector, curbing illegal wood harvesting had already begun by Ghana's Forestry Commission through its internal mechanisms. This made it easier to accept and ratify an external program by the EU which directly was to feed into the already prevalent processes and intentions of the Forestry Commission to foster good governance in the forestry sector.

Sustainable Management of Forest Resources 
Vol. 06, No. 04; 2021

ISSN: $2456-8643$

A major goal of Ghana's decision to ratify the EU VPA was to promote sustainable management of forest resources in the country. The idea of sustainable management of forest and timber has been a very important goal of government and a program which seeks to reinforce this objective was a welcoming news.

\section{Curbing Illegal Chain Saw Operations and Forest Degradation}

The inception of VPA has been a way of rekindling and also to justify efforts at reducing illegal chain saw activities in the country.

\section{Enhancing and Sustain the Trade Relationship with the EU}

The European Union has been the major trade partner with Ghana and the timber from Ghana has traditionally seen the EU market as its destination point. Henceforth, Ghana responded to the call to promote openness and transparency in the forestry sector in order to maintain her relationship with her strategic timber trading partner (EU).

\section{A Form of Fear and Initial Reservations}

Beyond the intrinsic desire to protect forest resources and to sustain forest management in Ghana, respondents also indicated that some form of fear and an apparent threat or conditionality inherent in the VPA process. Although not very explicit, it was implied and subtly embedded in the VPA model

\section{2: The Institutional Structures for Implementing the VPA in Ghana Definition of Legal Timber}

The introduction of the VPA has seen a Timber Resources Management and Licensing Legislature considered for enactment to conceptualize what constitutes 'legal timber' in the Ghanaian context as well as the processes for maintaining sustainable forest management. With the VPA, the EU does not dictate what exactly a legal timber is but relies on the exporting member country to use its domestic laws to determine and document legal timber. A main cardinal principle of the VPA/Legality Assurance System is the definition of legal timber in Ghana.

\section{Chain of Custody (GWTS)}

A main system and procedure to foster the VPA implementation is the Ghana Wood Tracking System (GWTS) which acts as a chain of custody that identifies all trees and potential timber unto a software to facilitate the monitoring of wood harvesting. This is an electronic system that keeps a database of all trees within a concession in order to check and address illegality. This system has been structured to ensure openness, verification and cross checking of data on trees which by all standards helps foster sustainable management of forests.

\section{Verification (Field Audit)}

Enforcement of the VPA has come with it a Verification System which involves an internal field audit to oversee the extent to which there is conformity to the Legality Assurance System (LAS). More importantly, the internal auditors recheck whether the data captured and entered unto the Ghana Wood Tracking System (GWTS) is accurate and adequately reflects the field conditions. 
The audit process ensures continuous compliance and applies punitive measures to adverse management of forest resources.

\section{Independent Monitor}

Beyond the internal mechanisms of the Forestry Commission to help ensure compliance to the legality assurance through internal audit and verification processes, there are other independent monitoring mechanisms to help in triangulating the verification process. This mechanism makes provision for a specialized individual to ensure all tenets in the processes and standards are complied with. An independent monitor who watches and reports on the processes helps in no small measure inject more transparency in the activities of the forest officers.

\section{Transparency and Accountability in Forest Governance}

The VPA processes and structures which are enforced have helped in opening up the forest and timber trade space to ensure that there is transparency and accountability in the process.

\section{Actors, Governance and Monitoring}

To ensure that established regulations are enforced effectively, the new governance regime has in place different stakeholders or actors who are involved in the governance and monitoring of timber activities from source before export. The main actors include independent auditors (external monitors), civil society organizations/ non-governmental organizations as well as the TVD (internal auditors).

\section{Training and Capacity Building for Forestry Staff}

Before the operationalization of the VPA, relevant enforcement agencies and stakeholders have been taken through series of training sessions and the provision of relevant logistics to facilitate the enforcement process.

\subsection{VPA Implementation and Timber Exploitation in Ghana}

\section{Reduction in Illegal Logging}

The data revealed that the introduction of the VPA and its intrinsic elements have practically contributed to a reduction in illegal logging.

\section{Multi-tier Transparency}

The VPA process has introduced different accountability and transparency mechanisms along the timber trade value chain especially the introduction of independent monitor and technology for tracking wood source. In a survey with respondents, they expressed positive opinions on VPA and accountability.

\section{Prompt Payment of Timber Royalties}

The timber trade is expected to benefit the state in terms of revenue, the private timber firms in terms of profits and more importantly the community members through royalties. The latter had 
been problematic over the years as there had been reports of delayed or unpaid royalties over time.

\subsection{Challenges in the Implementation of the Voluntary Partnership Agreement Logistical Constraints and Cost}

A major challenge which affects the effective implementation of the VPA is the issue of poor network connectivity. This is a big blow to the VPA implementation because significant aspects of the process is electronic and network based hence would ideally require information technology devices such as specialized laptops, GPS devices, and reliable connectivity of the systems at the national level, district levels and the field.

\section{Red Flags}

It also emerged from the study that the computation process where field officers code trees and timber unto the software sometimes pops up entry errors. This is what is termed as red flags which may suggest either a wrong doing on the part of an official or technical problem. In situations where the software generates many red flags, it becomes more frustrating to field officials when genuinely there has not been any tempering of the tree species or software.

\section{Institutional Capacity of Actors not Fully Developed}

The study found out that technical know-how of implementation officials at the FC has not been fully developed to match up with the new tasks that VPA enforcement has brought.

\section{Inter-Agency Coordination}

Very related to the capacity challenge above, the study observed laxities in inter-institutional coordination in the implementation of VPA. In other words, collaboration between relevant agencies and institutions for the purpose of VPA implementation is problematic since there are noclear-cut regulations which explicitly clarify the roles or functions of each actor.

\section{Illegal Domestic Timber Trade}

It emerged from the study that the domestic timber trade has been a torn in the flesh of the VPA implementation since it provides a market for timber from illegal source. The point is that once there is a ready market for such products, suppliers will try all means to meet the demands.

\section{Uncooperative Attitude of Domestic Operators}

The study also observed some undercurrents of some reservations among local timber merchants who think the strict enforcement of VPA and its timber legalities will affect their interest.

\section{CONCLUSIONS}

From the above findings, the study draws the following conclusions:

The study concludes that a policy even if originates from external source is more likely to be embraced if it does not challenge but feeds into government's prevalent activities, the legitimacy of that agreement/policy and enforcement remains higher. 
Vol. 06, No. 04; 2021

ISSN: $2456-8643$

Secondly, the VPA is an external mechanism which has been localized and infused with ongoing projects to provide novel and innovative mechanisms for supporting Ghana's desires and quest to manage forests better, improve peoples' livelihoods, and protect natural resources

Thirdly, the VPA has established a policy and legality assurance, in its operationalization it has also established some remarkable structural and institutional processes to help in a comprehensive realization of its main objective of enhancing sustainable forest practices.

In addition, the study concludes that the technology associated with VPA has enabled an improvement in tracing the origin of lumber from any point which is a novel step in fighting illegal logging and promoting sustainable forest management in Ghana. A Tracking System (WTS) which has been introduced into the Ghanaian forestry sector (Ghana Wood Tracking System) to operationalize a chain-of-custody system, has assisted in tracking the transportation of wood from the forest, along the entire supply chain, up to the point of export.

The study concludes that the structural and processual mechanisms associated with VPA (GWTS, verification and validation system, independent monitor) promote provide practical measures which motivate and compel timber firms to adopt sustainable forest practices in their logging and timber trading activities.

The role of independent monitors, verification officers, multiple actors and the tendency for the GWTS to access reality in real time all serve as a check to increase trust in the VPA arrangement and enforcement process. Individuals, either as forestry officials or private timber operators at any point in time will be conscientious and relatively honest in their dealings because the value chain has lots of checks and independent verification mechanisms.

Despite the inherent strengths associated with the VPA, its implementation has, nonetheless, been hampered due to logistical constraints as well as imposition of additional cost to the Forestry Commission. Although the VPA is laudable idea of using IT in effectively tracking timber to its original source to ascertain legality or otherwise of the timber, the needed IT infrastructure and resources have not matched up with the goal. Additionally, the VPA implementation is expensive and has come with additional cost to the FC, the study concludes that without proper mechanisms of funding the VPA upon expiration of the initial project, the VPA is likely to face deep-seated challenges.

The study observes that institutional capacities of the relevant FC officials have not been sufficiently developed to enforce the VPA which leads to some implementation errors in the process. The study concludes that the increasing red flags that are raised on the GWTS software is a blend of technical errors emanating from negligence or capacity challenges and human manipulation. This calls for regular consultations and workshops with relevant stakeholders in order to assess which skills are deficient and a need to beef up through on-the-job training.

Despite the VPA is implemented via various agencies along the timber value chain, the study observes that inter agency-coordination has not been properly enhanced. The study concludes 
Vol. 06, No. 04; 2021

ISSN: $2456-8643$

that institutional coordination has been an issue which constrains the full optimization of the VPA implementation process.

Finally, the domestic market tends to fuel demand for illegal timber hence a constraint to the full realization of the VPA objective. The VPA tends to use demand for timber products as a condition to compel loggers or companies comply with legality standards yet the illegal domestic timber trade provides ready market to every timber irrespective of its source.

\section{REFERENCE}

Ahimin, A. O., Mikissa, J. B., Johnson, S., N’GuessanKouamé, F., \&Kamanzi, K. (2019). Implementing principles, criteria and indicators for sustainable forest management in Gabon. Journal of sustainable forestry, 38(1), 46-53.

Andrée, B. P. J., Chamorro, A., Spencer, P., Koomen, E., \&Dogo, H. (2019). Revisiting the relation between economic growth and the environment; a global assessment of deforestation, pollution and carbon emission. Renewable and Sustainable Energy Reviews, 114, 109221.

Arts, B., Leroy, P., \& van Tatenhove, J.,(2006). Political modernisation and policy arrangements: a framework for understanding environmental policy change. Public Organizational Review 6, 93-106.

Baig, M. B., Pulhin, J., El-Juhany, L., \&Straquadine, G. S. (2019). Ensuring sustainability in forests through the participation of locals: implications for extension education. In Climate Change, Food Security and Natural Resource Management (pp. 323-360). Springer, Cham.

Balsiger, J., \&VanDeveer, S. D. (2012). Navigating regional environmental governance. Global Environmental Politics, 12 (3), 1-17

Commission on Global Governance (2015). Our Global Neighbourhood, Oxford: Oxford University Press.

Creswell, J. W. (2013). Research design: Qualitative, quantitative, and mixed methods approaches. Thousand Oaks, CA: Sage.

Demers, M (2005). Governance: Concepts and Applications. IIAS Working Group, International Institute for Administrative Studies, Brussels

Dlamini, C., \&Montouroy, Y. (2017). Governing Sustainable Forest Management Issues in Polycentric Governance: The EU FLEGT Action Plan as a Regulatory Catalyser. Environmental Law Review, 19(1), 6-29.

dos Muchangos, L. S., Tokai, A., \&Hanashima, A. (2017). Stakeholder analysis and social network analysis to evaluate the stakeholders of a MSWM system-A pilot study of Maputo City. Environmental Development, 24, 124-135.

Faggin, J., \&Behagel, J. (2018). Institutional bricolage of Sustainable Forest Management implementation in rural settlements in Caatinga biome, Brazil. International Journal of the Commons, 12(2).

Fasona, M., Adeonipekun, P. A., Agboola, O., Akintuyi, A., Bello, A., Ogundipe, O., ... \&Omojola, A. (2019). Incentives for collaborative governance of natural resources: A 
Vol. 06, No. 04; 2021

ISSN: $2456-8643$

case study of forest management in southwest Nigeria. Environmental Development, 30, 76-88.

Graham, J., \& Plumptre, T. (2003). Governance principles for protected areas in the $21^{\text {st }}$ century. Institute On Governance, Ottawa, Canada

Houghton, R. A., \&Nassikas, A. A. (2018). Negative emissions from stopping deforestation and forest degradation, globally. Global change biology, 24(1), 350-359.

IPCC (2007), Fourth Assessment Report. International Panel on Climate Change. Available at https://www.ipcc.ch/assessment-report/ar4/ (Accessed on 12 January, 2018)

Jafari, A., Kaji, H. S., Azadi, H., Gebrehiwot, K., Aghamir, F., \& Van Passel, S. (2018). Assessing the sustainability of community forest management: A case study from Iran. Forest policy and economics, 96, 1-8.

John W. Creswell \& Vicki L. Plano Clark. (2017). Designing and Conducting Mixed Methods Research..

Kahsay, G. A., \&Bulte, E. (2019). Trust, regulation and participatory forest management: Microlevel evidence on forest governance from Ethiopia. World Development, 120, 118-132.

Maraseni, T. N., Bhattarai, N., Karky, B. S., Cadman, T., Timalsina, N., Bhandari, T. S., ... \& San, S. M. (2019). An assessment of governance quality for community-based forest management systems in Asia: Prioritisation of governance indicators at various scales. Land use policy, 81, 750-761.

Neuman, W. L. (2007). Basics of social research: Qualitative and quantitative approaches (2nd ed. ; International ed.). Boston, Mass; London: Pearson, Allyn and Bacon..

Olson, H. (1999). Quantitative "versus" qualitative research: The wrong question. [Online] Available: http://www.ualberta.ca/dept/slis/cais/olson.htmPark, M. \&Youn, Y. (2013) Development of urban forest policy-making toward governance in the Republic of Korea. Urban For. Urban Green, 12, 273-281

Plummer, R., \& Fitzgibbon, J. (2004). Co-management of natural resources: a proposed framework. Environmental management, 33(6), 876-885.

Rhodes, R. A. W. (1996). The new governance: governing without government. Political studies, 44(4), 652-667.

Riccioli, F., Fratini, R., Marone, E., Fagarazzi, C., Calderisi, M., \&Brunialti, G. (2019). Indicators of sustainable forest management to evaluate the socio-economic functions of coppice in Tuscany, Italy. Socio-Economic Planning Sciences, 100732.

Roche, M, (2017). "Forest governance and sustainability pathways in the absence of a comprehensive national forest policy - The case of New Zealand," Forest Policy and Economics, Elsevier, vol. 77(C),33-43

Salpakivi-Salomaa, P. (Eds.). Forest in the cache. The biodiversity of Finland's forestry. Edita, Helsinki. pp. 210-214

Sampford, C. (2002). Environmental governance for biodiversity. Environ. Sci. Policy 5(1), 7990

Thompson, I., Mackey, B., McNulty, S. \&Mosseler, A. (2009). Forest Resilience, Biodiversity, and Climate Change. A synthesis of the biodiversity/resilience/stability relationship in forest ecosystems. Secretariat of the Convention on Biological Diversity, Montreal. Technical Series no. 
Tritsch, I., Le Velly, G., Mertens, B., Meyfroidt, P., Sannier, C., Makak, J. S., \&Houngbedji, K. (2020). Do forest-management plans and FSC certification help avoid deforestation in the Congo Basin?Ecological Economics, 175, 106660.

Tuxill, J., \&Nabhan, G. P. (2011). People, Plants and Protected Areas. Earthscan Publications, London, UK.

UNDP (2013). Governance for Sustainable Human Development, New York: UNDP.

Van Gossum, P., Arts, B., Wulf, R., \& de Verheyen, K. (2011). An institutional evaluation of sustainable forest management in Flanders. Land Use Policy, 28, 110-123

Van Tatenhove, J.P.M.; Arts, B.; Leroy, P. Political Modernization and the Environment: The Renewal of Environmental Policy Arrangements; Kluwer Academic Publishers: Dorerecht, The Netherlands, 2000

Veenman, S., Liefferink, D., Arts, B. (2009). A short history of Dutch forest policy: The "de institutionalisation" of a policy arrangement. For. Policy Econ., 11, 202-208

White, J. D. (1999). Taking language seriously: The narrative foundations of public administration research. Washington, D.C.: Georgetown University Press.Wiersum, K. F. (1995). 200 years of sustainability in forestry: lessons from history. Environmental management, 19(3), 321-329.

Wiering, M. A., \& Arts, B. J. M. (2006). Discursive shifts in Dutch river management: 'deep 'institutional change or adaptation strategy? In Living rivers: trends and challenges in science and management (pp. 327-338). Springer, Dordrecht.

World Bank (2001). Governance, The World Bank's Experience, Washington, DC: The World Bank.

Yamaki, K. (2017). Applying social network analysis to stakeholder analysis in Japan's natural resource governance: two endangered species conservation activity cases. Journal of Forest Research, 22(2), 83-90.

Yin, R. K. (2003). Case study research: design and methods. Thousand Oaks, Calif, Sage Publications.

Yin, R. K. (2017). Case study research and applications: Design and methods. Thousand Oaks, CA: Sage.. 